\title{
Iranian Traditional Bathhouse: Relationship between mental health and geometric features
}

\author{
Sima Mansoori*, Mohsen Faizi, Farhang Mozaffar, Bahram Saleh Sedgh Pour \\ Faculty of Architecture and Urbanism, I.U.S.T, Tehran, Iran.
}

\begin{abstract}
To develop health, it is necessary to pay attention to different dimensions of social settings, abilities, and affordance. Behavioral bathhouses compared to the modern day bathrooms are different regarding meanings, function, and properties. The research method in this paper is qualitative using the Grounded Theory methodology. The aim of this paper is to investigate the relationship between the mental health of users and the geometric features (shape \& form) of Iranian bathhouses. In conclusion, the research finding revealed that the geometric features of traditional bathhouse of Iran made the different dimensions of mental health.
\end{abstract}

(C) 2016. The Authors. Published for AMER ABRA by e-International Publishing House, Ltd., UK. Peer-review under responsibility of AMER (Association of Malaysian Environment-Behaviour Researchers), ABRA (Association of Behavioural Researchers on Asians) and cE-Bs (Centre for Environment-Behaviour Studies, Faculty of Architecture, Planning \& Surveying, Universiti Teknologi MARA, Malaysia.

Keywords: Bathhouse; bathroom; geometric shapes; healing

\section{Introduction}

To develop health, it is necessary to pay attention to different dimensions of social settings, abilities, and affordance. In the Traditional Architecture of Iran (TAI), knowing how to use "Social Engineering" is critical since behavior has a healthier and qualitative welfare function in the constructed environment. Humans used to live in natural settings. The natural elements play a fundamental role in all aspects of life, from organizing the structure of a city to habitats and from nutrition to the use of local and renewable materials. "A healthy architecture and urban planning are one of the most challenging issues in the contemporary era. Unfortunately, nowadays, human beings jeopardize their health by living in modern urban spaces, modern cities, and especially modern residential buildings. Therefore, it is evident that we are in need of a socio-behavioral approach to establishing more healthy social settings" (Mahdavinejad \& Mansoori, 2012). Nowadays, the increase in the number of patients has become more rapid than before. Given the growing consciousness concerning health and diseases, social settings have taken on a responsibility for the prevention of diseases and the achievement of health. "New trends and changes have been recorded in the medical sector, stimulated by the new politics of prevention promoted by the W.H.O. Experts approve and sustain the active use of natural therapies. It includes the performance of a physical activity that has been adopted both for treatment and prevention (Natural Therapeutic Ingredients and Cures). The renewed use of traditional therapeutic principles for treatment and prevention also seen in some newly built structures" (Di Cicco, 2004, p.123). Not only must hospital and clinic constructions be enhanced

\footnotetext{
${ }^{*}$ Corresponding author. Tel.: +0-000-000-0000

E-mail address: mansouri.sima@gmail.com
}

(C) 2016. The Authors. Published for AMER ABRA by e-International Publishing House, Ltd., UK. Peer-review under responsibility of AMER (Association of Malaysian Environment-Behaviour Researchers), ABRA (Association of Behavioural Researchers on Asians) and cE-Bs (Centre for EnvironmentBehaviour Studies, Faculty of Architecture, Planning \& Surveying, Universiti Teknologi MARA, Malaysia.

DOI: http://dx.doi.org/10.21834/e-bpj.v111.211 
from the architectural design, but all social environments in the city also need to have a healthy approach to the principle of construction and design. One of the behavioral settings, which plays a vitally healthy and therapeutic role in the Traditional Medicine of Iran (TMI) is the "Traditional Bathhouse Of Iran". In the traditional architecture of Iran (TAI), many traditional bathhouses seem to have a therapeutic function. Nowadays, the Traditional Bathhouse of Iran (TBI) has left the fundamental function and has been changed to a museum or a traditional restaurant or a coffee shop (Ganjalikhan Kerman, Vakil Shiraz, Soltanmirahmad Kashan). Behavioral bathhouses compared to the modern day bathrooms are different regarding meanings, function, and properties. The existence of hazards influences our healthy environmental conditions. Moreover, some factors related to the building and environment contribute to the increase in health disturbances and diseases called the "sick building syndrome" (Di Cicco, 2004). This paper surveys how geometric features of the built environment adversely impact human's mental health. Current bathrooms with contemporary patterns have been mostly underperforming. Disease-causing misfit designs with the lack of direct sunlight decreased areas oblivious to shape and form affect the physical and mental health of a human. "All this requires an approach to the design and organization of space that does not treat it, as so much architecture does, as an abstract geometrical construct, but as a social and psychological one. Although many of these ideas have been around for some time, much of the architectural practice still seems oblivious to them. Indeed, it turns out to be the case that the features of architecture that often dominate debate among the cognoscenti are often not those that impact most fundamentally on the quality of life" ( Lawson, 2010).

The aim of this paper is to investigate the relationship between the mental health of users and the geometric features (shape \& form) of Iranian bathhouses. This survey analyzes the physical and geometrical characteristics of the TBI with the goal of a comprehensive approach based on the Quality features. Secondly, the objective of this research is related to the consciousness and responsibility of builders and designers as an essential contribution towards sustainability of the building. The final purpose is the realization of 'healthy buildings'. "They take into consideration the prevention of concrete risks related to health and environment, the application of shape and form, energy saving, and future mental perspectives" (Di Cicco, 2004). It includes the mechanism of action that balances the human body. Bathhouse environments focus on optimizing the relationship between the individual and the geometrical features of the environment. The general wellbeing of the human includes psychological and physical benefits.

There are critical questions that this paper scrutinizes. Does the Iranian Traditional Bathhouse have a mental health function? Moreover, do the geometrical features of the Iranian bathhouse architecture lead to human's mental health? It is necessary to note that there is a significant difference in the meanings of "Bathhouse and Bathroom." In the past, why were Bathhouses used for cleaning, and why are Bathrooms used today? Which model is closer to health?

This research explores the level of importance of the built environment in the creation of health and a good built construction from the concepts of geometry regarding shapes and forms. A previous paper by the same author surveyed the fundamental criteria in health architecture in Iran (Mahdavinejad \& Mansoori, 2012) that were the key findings in this matter. The aim of the present paper is to discover the mystical concepts related to geometrical features of the TBI that influence mental health.

\section{Literature Review}

\subsection{Geometry: features of shape and form}

A geometric method by which all shapes can be 'projected together' is linked by the unbroken thread of the generative process, to signify the visible and the intelligible. According to the co-relation most often encountered in latent architecture, we will discuss the meaning of the most important shapes thus far. The cube and square are the symbols of gross manifestation of the earth and a man's body. The octahedron and octagon are intermediaries, thus the symbol of mediation of the subtle indication of the atmosphere of a man's psyche. The sphere and the circle are the symbols of the most 'perfect' heavenly, causal manifestation, of the sky and a man's spirit (Kollar, 1975)

\subsection{The symbol of the circle}

Dr. M.-E. Von Franz explained the circle (or sphere) as a symbol of the Self. It expresses the totality of the psyche in all its aspects, including the relationship between man and the whole of nature. The spatial orientation performed may be regarded as symbolic of the human need for psychic orientation. The four functions of consciousness as described by Dr. Jung in his book including thought, feeling, intuition, and sensation, equip a man to deal with the impressions of the world he receives from within 
and without. It is using these functions that he comprehends and assimilates his experience; it is using them that he can respond. In the visual art of India and the Far East, the four or eight-rayed circle is the usual pattern of religious images that serve as instruments of meditation (Jung, 2011, p.240). Finally, Jung mentioned that the circle is a symbol of the psyche (Jung, 2011).

\subsection{Legibility of place}

Places should create with spatial legibility. That is to say, places should be made for people to understand and to find their way around. We move around using our mental map of the world. Places that are confusing prevent us from building that plan and add to stress levels. Designs should have some hierarchy of space, so that public and private places are clearly marked, entrances and exits are visible, and different parts of a building have different qualities (Lawson, 2010)

\subsection{Bathroom Prototype and Repeated Patterns}

"Bathhouse buildings follow an intricate architecture.... Every bathhouse consists of two principal areas. The first area known as the "SARBINEH." It is a cloakroom where callers undress in preparation for bathing or put their clothes on before exiting the bathhouse and the second is the "GARM-KHANEH", a "caldarium" where washing takes place. The MIAN-DAR located at the entrance of the bathhouse and the "GARM-KHANEH". The air inside is kept moderate to prevent visitors from suffering abrupt temperature changes between the cold outside and the hot, "GARM-KHANEH". It is designed to create a circuitous path impeding the exchange of heat and moisture between the bathhouse and the outside" (Ganjnameh, 2008).

\subsection{Health and Healing Environment}

The influence of the physical environment towards human behavior is well established in the literature, for example, in studies by Bechtel and Curchman (2002), Cassidy (2006), and Abbas and Ghazali (2011). "A healing environment can be described as the overall environment (physical and non-physical) created to aid the recovery or healing process" (Abbas \& Ghazali, 2010). Also, more human habitation creates more breeding sites for the mosquitoes even during the construction phase where there are receptacles capable of holding stagnant water. The emerging communicable diseases such as dengue and malaria also shrink the overall quality of life. In a way, these circumstances signal that something is wrong with the way we manage urban planning and its repercussion on the natural environment (Shafie \& Omar, 2013).

\section{Methodology}

This paper uses the qualitative approach as the research method to report the descriptive analysis and conclusion. Moreover, to achieve the aim of the research, the "Grounded Theory Research" has been used (Strauss, Anselm L., \& Carbine, Juliet, 2013). The "Grounded Theory Research" is based on open coding from the concepts of interviews with experts and the ideas of these experts are categorized into several components, which evoke the whole spectrum. Data extracted from 11 case studies of the TBI from 11 cities (Table 1), and they are categorized and analyzed, and ultimately conclusions are made. Data gathering was done through library research and by analyzing the TBI documents and semi-structured interviews with 11 experts. Open coding is done in response to the following questions:

What are the latent concepts in geometry features (shape and form)?

Experts were questioned to find new ideas and concepts of the scientific theory. Interviews were done with four professors from the School of Architecture, University of Science and Technology, Tehran, Iran, four Ph.D. students of Psychology, two psychiatrists, and one professional architect. The open coding method was used to describe the concepts, and the analysis compared the case studies obtained through axial coding. For each geometry shape, 18 ideas were sorted by three conventional components of the same degree. Each part of the six classified concepts include (1) Structure; (2) Semantic; and (3) Health and healing (Figures 1, 2, 3, 4, \& 5). The analysis measured the features of the bathhouse using compatible components as well as the role and impact of health and healing of the TBI on mental health. Finally, compliance features obtained the continuums using the open coding of the concepts, the axial coding of the components and the categories, respectively. 


\subsection{The number of case studies}

In this method, besides the necessity of the number scales, the fundamental roles of the data are also significant; therefore, the samples were not comprehensiveness and quality of the samples chosen. (Table 1).

Table 1. Chosen Bathhouses for coding source: authors

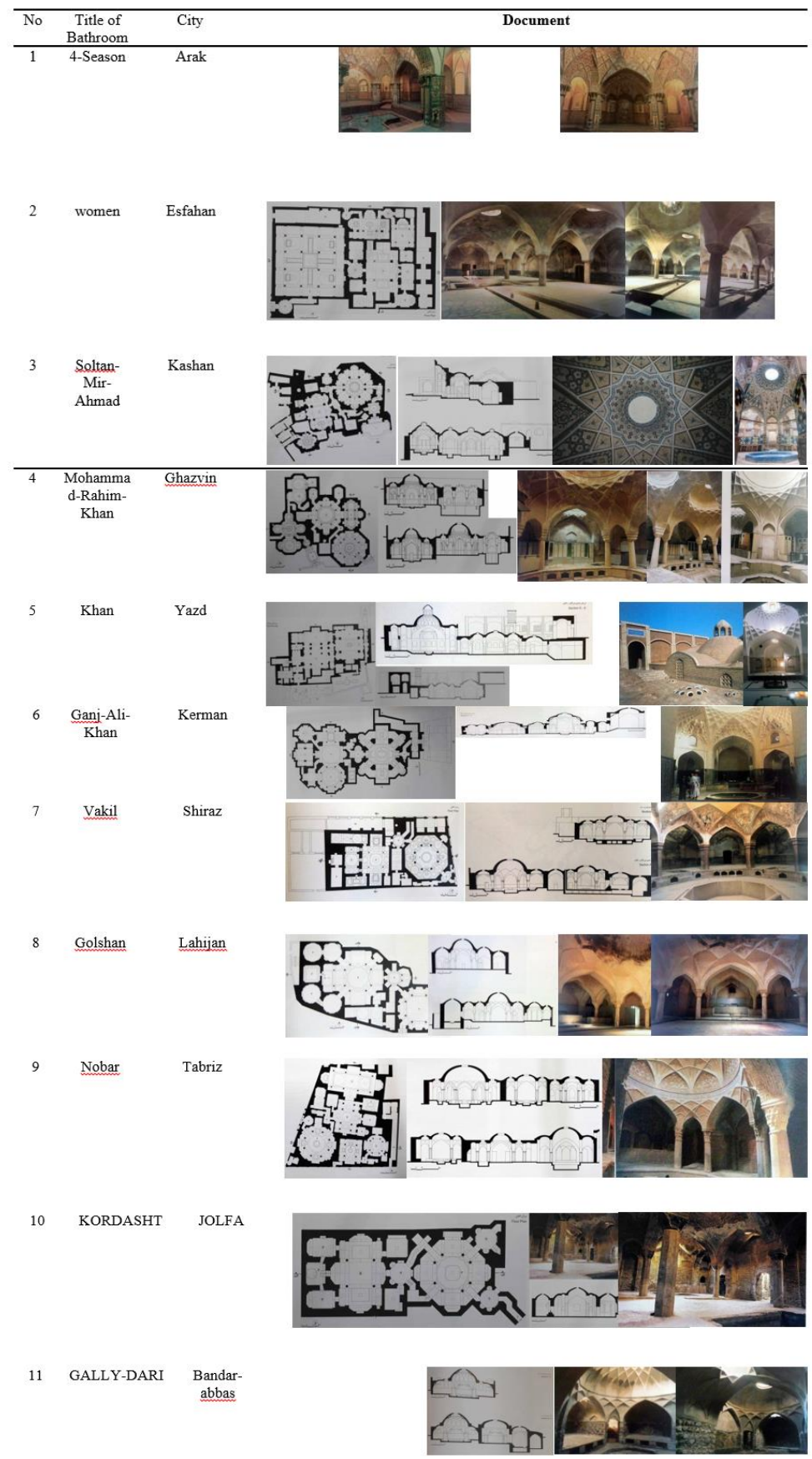


TBI documents included plans for classes, sections, and photos of the interior;

The examined spaces in this research based on geometry features included the "SARBINEH", "MIAN-DAR", and "GARMKHANEH"; and

The spaces in this research were examined based on the role of function, communication, health, and healing.

Table 2. Survey The Geometry Of The forms studied in 11 selected case study source: authors

\begin{tabular}{|c|c|c|c|c|c|c|}
\hline No & $\begin{array}{l}\text { Geometry } \\
\text { of } \\
\text { SARBINEH }\end{array}$ & $\begin{array}{l}\text { Geometry of } \\
\text { MIAN-DAR }\end{array}$ & $\begin{array}{l}\text { Geometry } \\
\text { of } \\
\text { GARM- } \\
\text { KHANEH }\end{array}$ & $\begin{array}{l}\text { Geometry } \\
\text { of } \\
\text { CHALE- } \\
\text { HOZE }\end{array}$ & $\begin{array}{l}\text { Geometry } \\
\text { of } \\
\text { KHAZINEH }\end{array}$ & $\begin{array}{l}\text { Geometry } \\
\text { of } \\
\text { KHALVAT }\end{array}$ \\
\hline $\begin{array}{l}\text { 4season } \\
\text { Arak }\end{array}$ & $\begin{array}{l}\text { Octagon } \\
\text { regular }\end{array}$ & Octahedron & Cruciform & - & Tetrahedron & Tetrahedron \\
\hline $\begin{array}{l}\text { Women } \\
\text { Esphebaan }\end{array}$ & Square & $\begin{array}{l}\text { Octagon } \\
\text { regular } \\
+ \\
\text { Rectangle }\end{array}$ & Rectangle & - & Rectangle & Octahedron \\
\hline $\begin{array}{l}\text { Soltan-Mir- } \\
\text { Ahmad } \\
\text { Kashan }\end{array}$ & $\begin{array}{l}\text { Octagon } \\
\text { regular }\end{array}$ & $\begin{array}{l}\text { Rectangle } \\
\text { \& } \\
\text { Irregular form }\end{array}$ & Rectangle & - & Rectangle & Rectangle \\
\hline $\begin{array}{l}\text { Mohammad- } \\
\text { Rahim-Khan } \\
\text { Ghazvin }\end{array}$ & $\begin{array}{l}\text { Octagon } \\
\text { regular }\end{array}$ & $\begin{array}{l}\text { Rectangle } \\
\& \\
\text { Irregular form }\end{array}$ & Octahedron & Rectangle & Rectangle & Octahedron \\
\hline $\begin{array}{l}\text { Khan } \\
\text { Yazd }\end{array}$ & Cruciform & Rectangle & Rectangle & Rectangle & Rectangle & Rectangle \\
\hline $\begin{array}{l}\text { Ganj-Ali- } \\
\text { Khan } \\
\text { Kerman }\end{array}$ & Icosahedron & dodecahedron & Cruciform & $\begin{array}{l}\text { Octagon } \\
\text { regular }\end{array}$ & Rectangle & Octahedron \\
\hline $\begin{array}{l}\text { Yakil } \\
\text { Shiraz }\end{array}$ & $\begin{array}{l}\text { Octagon } \\
\text { regular }\end{array}$ & $\begin{array}{l}\text { Octagon } \\
\text { regular } \\
\& \\
\text { Rectangle }\end{array}$ & Cruciform & - & Rectangle & Rectangle \\
\hline $\begin{array}{l}\text { Golshan } \\
\text { Lahijan }\end{array}$ & $\begin{array}{l}\text { Octagon } \\
\text { regular } \\
\& \\
\text { Sixteen- } \\
\text { sided }\end{array}$ & $\begin{array}{l}\text { Octagon } \\
\text { regular } \\
\& \\
\text { Irregular form }\end{array}$ & Cruciform & - & Square & $\begin{array}{l}\text { Octagon } \\
\text { regular }\end{array}$ \\
\hline $\begin{array}{l}\text { Nobar } \\
\text { Tabriz }\end{array}$ & $\begin{array}{l}\text { Octagon } \\
\text { regular }\end{array}$ & $\begin{array}{l}\text { Irregular form } \\
\& \\
\text { Winding form }\end{array}$ & Cruciform & Icosahedron & Rectangle & Rectangle \\
\hline $\begin{array}{l}\text { KORDASHT } \\
\text { JOLFA }\end{array}$ & $\begin{array}{l}\text { Octagon } \\
\text { regular }\end{array}$ & $\begin{array}{l}\text { Octagon } \\
\text { regular } \\
\& \\
\text { Irregular form }\end{array}$ & Cruciform & - & Rectangle & Rectangle \\
\hline $\begin{array}{c}\text { Galley-Dari } \\
\text { Bandar- } \\
\text { abbas }\end{array}$ & Cruciform & Rectangle & Cruciform & - & Rectangle & Rectangle \\
\hline
\end{tabular}

The examined spaces in this research regarding the role of function, communication, health and healing (Table 3)

\subsection{Scale and Compilation of Research}

The research conducted on two scales (middle-scale and small scale). The hierarchical access, the arrangement of spaces, and the entrance to private areas fall under the middle-scale. The small scale includes the form and geometry concepts as the most important characteristics of each field. In the present paper, the three sets of analyzed factors are: (1) the characteristics of shape and geometry of the environment; (2) the hierarchical arrangement of spaces and features, and the transposition of one space to another; and (3) the health and healing environment of the TBI. Moreover, emotional and behavioral feedback from placement in a variety of geometric areas through interviews with experts was contemplated. The profile of this research is the interaction between the factors (Table 3). 
Table3. The Relation Between Chosen Spaces And The healing and healthy of the bathhouse. Source: authors

\begin{tabular}{lllllll}
\hline $\begin{array}{l}\text { Name of } \\
\text { space }\end{array}$ & $\begin{array}{l}\text { SARBI } \\
\text { NEH }\end{array}$ & $\begin{array}{l}\text { MIAN- } \\
\text { DAR }\end{array}$ & $\begin{array}{l}\text { GARM } \\
\text { KHAN } \\
\text { EH }\end{array}$ & $\begin{array}{l}\text { KHAZ } \\
\text { INEH }\end{array}$ & $\begin{array}{l}\text { CH } \\
\text { AL }\end{array}$ & $\begin{array}{l}\text { KHA } \\
\text { LVA }\end{array}$ \\
& & & & & $\begin{array}{l}\text { HO } \\
\text { ZE }\end{array}$ \\
\hline $\begin{array}{l}\text { Runction } \\
\text { Relevan } \\
\text { ce space }\end{array}$ & & $*$ & & & & \\
$\begin{array}{l}\text { Health } \\
\text { Healing }\end{array}$ & & & $*$ & $*$ & $*$ & $*$ \\
\hline
\end{tabular}

In this research method, respondents were asked to respond to questions such as:

What are the relations between concepts and components?

What are the components obtained in the categorized ideas?

This pattern was obtained using the code. According to the "Grounded Theory" (Table 3) and the ideas from the open coding, the three conventional components include (1) Constructed and Unconstructed; (2) Semantic and Corporeal; and (3) Health and Semiotic (Figures 1, 2, 3, 4, \& 5).

Axial coding is done in response to the following questions:

What is the continuum of interaction between concepts and components?

What is the relationship between the continuums caused by the geometric shapes?

Which geometric shapes have similarities and differences between the continuums?

What would the relationship be among the interpretations of the continuum of spaces in the TBI?

It noted that the "Grounded Theory" is the appropriate method for finding new concepts in exploratory research.

There are limitations in measuring the influence of geometry features on mental health and how much the geometry influences the conscious and unconscious mind in the $\mathrm{TBI}$, as this needs a quantitative research.

\section{Findings}

For each shape, a "Box Coding" is performed. Three continuum lines are drawn across three axial coding. Finally, the consensus of the three ideas became the core concept, which located on a continuum line; for each shape, three core concepts are mentioned.
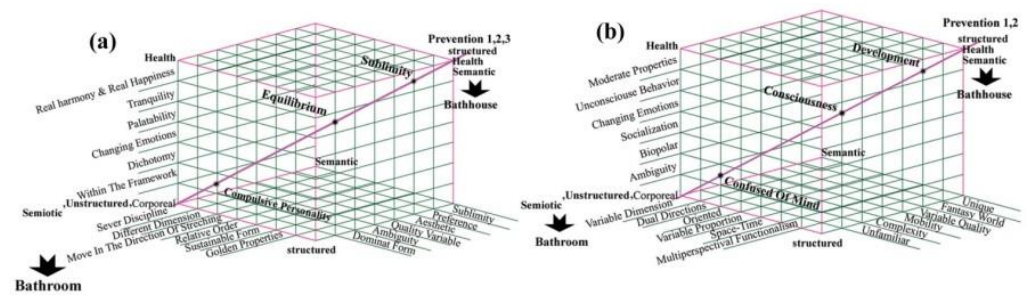

Fig. 1. Axial Coding Of Concepts; (a) Irregular Form; (b) Tetrahedron. Source: Authors 

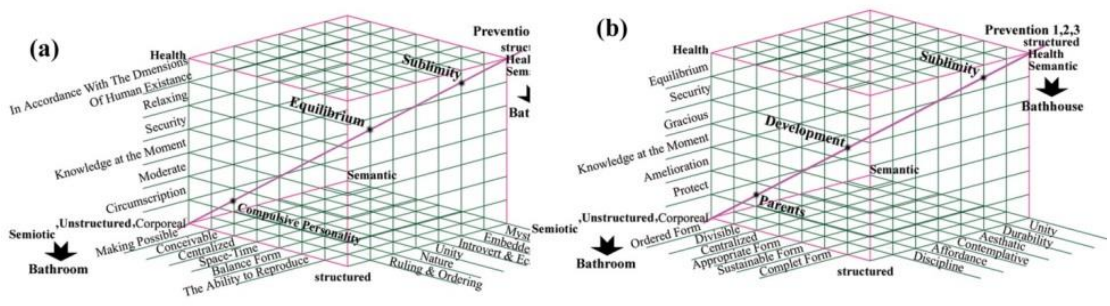

rIg. 2. Axıal Codıng Ut Concepts ; (a) Kectangle; (b) Uctagon. Source: authors
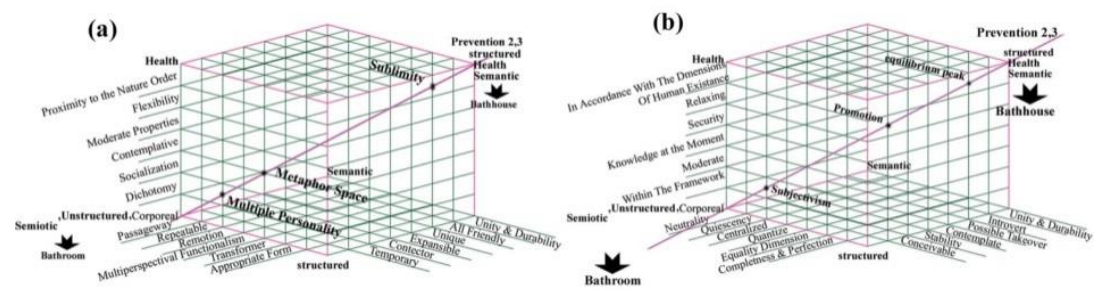

Fig. 3. Axial Coding Of Concepts; (a) Octagon Regular; (b) Square.

Source: authors.
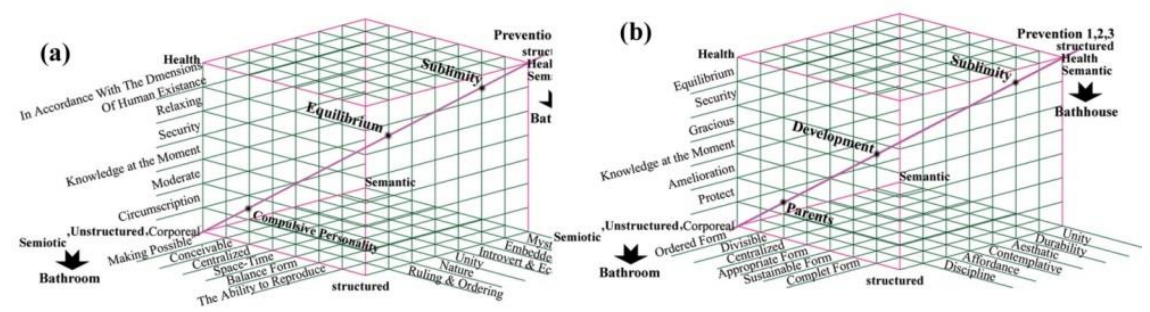

Fig. 4. Axial Coding Of Concepts; (a) Cruciform; (b) Dodecahedron \& Icosahedron Source: authors.

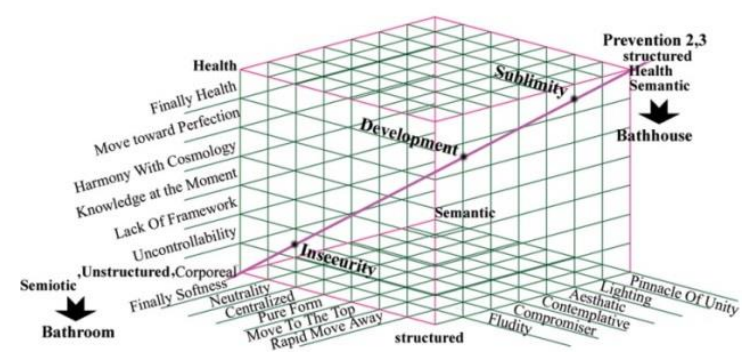

Fig. 5. Axial Coding Of Concepts; (a) Circle Source: authors. 
The most ordinary meaning in the context of the relevant continuum is "Sublimity". "Sublimity" means the super-eminence mental process that allocated to the highest degree of mental health. Sublimity found in Rectangle, Octagon Regular, Cruciform, Dodecahedron, Icosahedron, and Circle shapes. These forms commonly found in the "SARBINEH," "MIAN-DAR," "GARMKHANEH", and "KHALVAT." The second degree of the continuum is "Development". It means "Maturity" in all aspects of the mind moving towards a healthy mind. "Development" is relevant to geometric shapes such as Octagon, Dodecahedron, Icosahedron, and Circle. The third degree of the continuum is "Equilibrium". This concept is the base and the most important semantic for mental health, and it found in the Rectangle, Square, and Cruciform geometric shapes. It is seen in the "GARMKHANEH" based on the evidence from the Bathhouse documents. Regarding performance, health and healing are the most significant space in the TBI. The maximum time spent in the bathroom is in the "GARMKHANEH". Based on the results shown in Fig. 6, "Parents" and "Promotion" are of the same degree in the TBI. "Protective form," "Maintenance", and "Security" sectors are called the "Parents" concept. It seen in the Dodecahedron and Icosahedron shapes. Also, "Promotion" means affordance or a boost in high mental ability as observed in the Rectangle and Square shapes. "Metaphor," "Consciousness," "Remediable," "Efficient", and "This Time, This Place" have the same degree. "This Time, This Place" means the right person, a suitable place, and an appropriate time; Knowledge and the consciousness of space and time are behavioral characteristics of the environment. Moreover, "Efficient" is concerned with the individual's knowledge of self and the future. The meaning implies reasonable estimates. These same degrees of the continuum seen in Octagon Regular, Octagon, Tetrahedron, and Irregular forms that included in the spatial geometry of the different parts of the Bathhouse.

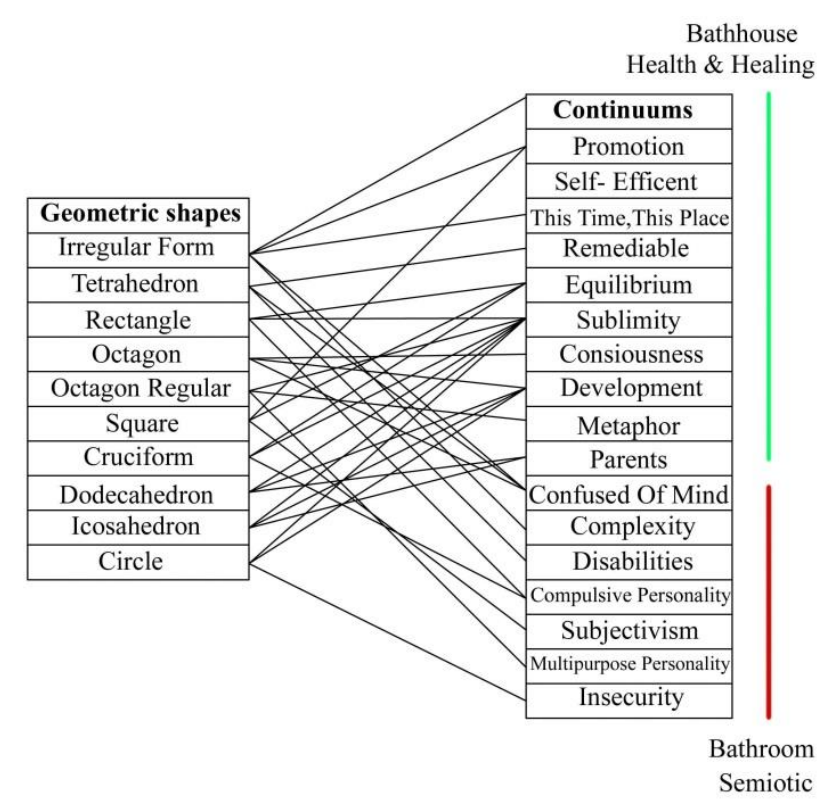

Fig 6. Final Findings Of The Relation between Geometric Shapes And Continuums (source: authors).

\section{Discussion and Conclusion}

"Health is not brought about by drugs, vitamins, or by developing the muscles of the body. It is the result of an active life in an environment rich in varied opportunities for mental and physical development with free and friendly social intercourse. Healthy people do not want to organize, but they do want opportunities to do things together" (Shoshkes \& Adler, 2009). Therefore, the approach towards "Social Medicine" is imperative; all professionals should involve in practical health and healing. As mentioned in the introduction, "Social Engineering" is the most important part of a healthy and healing environment, especially in a constructed environment. "Bathhouses" and "Bathrooms" are located across the spectrum of health and disease. Through the findings of the axial coding, it was found that the "Bathroom" does not have a Social aspect, and it mostly includes Unstructured, 
Semiotic, and Corporeal concepts. To find the "Bathroom Pathology," it is important to pay attention to ideas from the open and axial coding. It includes confusion, complexity, disabilities, enthusiastic personality, subjectivism, insecurity, and dichotomy. Thus, according to the system, architectural practices in creating healing environments are necessary. Nonlinear and dynamic systems govern the relationships between the components of higher ability. "According to the second law of thermodynamics, as soon as it opens (life), a closed system (dead) converts it to increase its entropy and destroys it. If the game that the entropy changes is zero, it will disintegrate and therefore, have an infinite life" (Naseri, 2013). The approach based on prevention before therapy. It is important to follow the discipline of prevention in the design and construct of behavioral settings. Primary prevention will try to prevent the disease, as a person not infected yet. Secondary prevention includes early detection, treatment, follow-up, and proper care to prevent the progression of intensity, thus reducing the damage. After this, in the third stage, a patient permanently suffers, and treatment cannot implement at this point. However, with rehabilitation procedures, recovery, and restoration, the patient can return to normal life (Fard Milani, 1984).

Implications beyond the confines of the current research using the practical findings can lead to policies on the use of geometry in the design with the aim of being fully capable of providing mental health to users.

"Health is a result of the complex interactions of people with each other and their physical and social environments. It has a crucial role in the health and survival of humanity" (Shoshkes \& Adler, 2009). They are far more concerned with the pathology of the environment than with the health criteria of the environmental design before the point of decision (Shoshkes \& Adler, 2009). The bathhouse provides social opportunities and the environment to grow and develop; it promotes sublimity among the people in a friendly manner in an intangible structure. Their important roles are in the protection of health in the form of primary prevention, secondary healing, and thirdly, therapy that focuses on prevention. Thus, the TBI has a healthy function and a relaxing atmosphere.

Recommendations for improving the quality of new bathrooms are necessary. Properties of shape and form in designs used should also pay attention to the effects on human's mental health and other aspects that affect human health.

\section{Further Research}

To investigate associations between the features of geometry and social health; and

To compare the influence of characteristics of geometry between social human health and mental health.

\section{References}

Strauss, A., and J. Corbin. (1990). Basics of Qualitative Research: Grounded Theory Procedures and Techniques. Newbury Park, CA: Sage Publications. Fard Milani, Behrooz.(1984). Children And Exceptional Adolescents Psychology. Publication :Q vs.ss, 121-127.

Shoshkes, Ellen., Adler, Sy.(2009). Planning for healthy people/healthy places: lessons from mid-twentieth century global discourse. Planning Perspectives, Vol. 24, No. 2, pp: 198, 202, 210. Routledge.

Abbas, Mohamed Yusoff., Ghazali, Roslinda.(2011). Physical Environment: The primary determinant towards the creation of a healing environment? ProcediaSocial and Behavioral Sciences.publisher: ELSEVIER.P1951

Mahdavinejad, Mohammadjavad ., Sima Mansoor. (2011). Architectural Design Criteria of Socio-Behavioral Approach toward Healthy Model. Procedia- Social and Behavioral Sciences.publish: ELSEVIER.P 478.

Abbas, Mohamed Yusoff and Ghazali, Roslinda.(2010). Paediatric Community: Healing Environment Conducive Enough? Procedia- Social and Behavioral Sciences . publisher: ELSEVIER.P 42.

Shafie, Farah., Omar, Dasimah. (2013). Environmental Health Impact Assessment and Urban Planning. Procedia- Social and Behavioral Sciences .publish By ELSEVIER.P 83.

-. (2008). Bathhouses. GANJNAMEH. Publisher: Rozanne.

Naseri, Masoud.(2013). Quantum mysticism and treatment DANAK theory and reviews through its philosophy of Homeopathic Medicine 12 edition, publisher triangle,pp133-136.

Kollar,I.peter.(1975). Symbolism in Christian architecture of the first millennium. Publisher: Sydney.

Jung, Carl G, at all.(1988).Man and his Symbols. 11 edition, Anchor Press.

Lawson, Bryan.( 2010).Healing architecture. Arts \& Health: An International Journal of Research, Policy and Practice. Publisher: Routledgep.103-104. 